\title{
INFLUENCE OF CORUNDUM AS COARSE AGGREGATE IN HIGH-PERFORMANCE CONCRETE ON PROJECTILE IMPACT RESISTANCE
}

\author{
Michal Mára*, ZdeŇKa ŘíhovÁ, Markéta KoČová \\ Czech Technical University in Prague, Faculty of Civil Engineering, Thákurova 7, 16629 Prague 6, Czech \\ Republic \\ * corresponding author: michal.mara@fsv.cvut.cz
}

\begin{abstract}
The aim of this paper is focused on the influence of corundum as coarse aggregate in high-performance concrete on projectile impact resistance in terms of depth of penetration and size of the crater. Based on the experimental programme, samples of high-performance steel-fibre-reinforced concrete with different types and quantities of coarse aggregates were designed and produced, to be subjected to impact loading in the form of projectile impact. Damaged samples were scanned using a 3D scanner and their surface was evaluated. The goal of the paper was to find the optimum content of coarse aggregate in the mixture in order to improve its resistance against projectile impact.
\end{abstract}

KEYWORDS: High-performance concrete, HPC, coarse aggregate, corundum, projectile impact, depth of penetration, crater surface, 3D scanning.

\section{INTRODUCTION}

In recent years, great emphasis is placed on durability, strength and safety of concrete structures, especially civil and military structures, which could be the target of deliberate or accidental shock loads. These structures, including objects of strategic importance, such as government buildings, reinforcements, defence shelters or other protective structures, must be resistant against this type of loads. These elements and their material are designed to withstand the possible extreme loads that can be caused by projectiles, fragments, explosions, cars or aircraft impact, earthquakes or terrorist attacks.

One of the materials that have a high potential to use for these structures is high-performance concrete with a dispersed steel reinforcement (HPSFRC). This research is focused on improving the resistance of HPSFRC slabs to projectile impact, with aiming to improve the properties while maintaining the thickness and weight of the slabs for easy handling. From previous studies [1 3] it is known that the increasing amounts of steel fibres over a certain limit worsens the workability of fresh concrete and lowers of compressive strength and modulus. For this reason, this work is focused on improving HPSFRC by adding coarse aggregate.

Concrete resistance against projectile impact depends on many aspects. Improved resistance against impact loads with respect to penetration depth and crater diameter can be achieved by reducing water/cement ratio and increasing compressive strength of concrete. The presence of dispersed steel fibres then decreases the diameter of the crater. For these reasons, the use of HPSFRC is the ideal solution for building structures that could be potentially exposed to impact loads. It is known that the conventional fibre-reinforced concrete (FRC) with normal strength matrix has a high energy absorption capacity when hit by a projectile. However, studies show that HPSFRC has a much greater energy absorption capacity in both quasi-static and dynamic loading [4].

The resistance of the concrete against the impact of the projectile is also affected by the size, strength and hardness of the added aggregate. In order to achieve the highest compressive strength, the presence of coarse aggregate in HPSFRC is usually reduced or even eliminated in order to achieve the required homogeneity and density of the mixture. The antipenetration capabilities of coarse aggregate have been therefore almost neglected. However, in the projectile penetration experiments performed by Zhang et al. [5], Langberg and Markeset [6] or Wu et al. [7, they found that the penetration depth of the projectile does not decrease as long as the compressive strength of the concrete reaches a certain boundary. The optimal compressive strength for HPSFRC, from which the protective structures will be constructed, has been designed to be $90-150 \mathrm{MPa}$ in terms of comprehensive considerations of effective protection and cost of production [4].

\section{MAterial AND MiXtures}

As a coarse material for HPSFRC, an artificial white corundum was chosen (Figure 1), mainly because of its very high hardness (Mohs hardness scale number 9) and its impact resistance. An experimental study with UHPSFRC with added corundum as coarse aggregate (UHP-CASFRC) was carried out by $\mathrm{Wu}$ 4], who focused on UHP-CASFRC samples with different contents and different corundum fractions. The sam- 


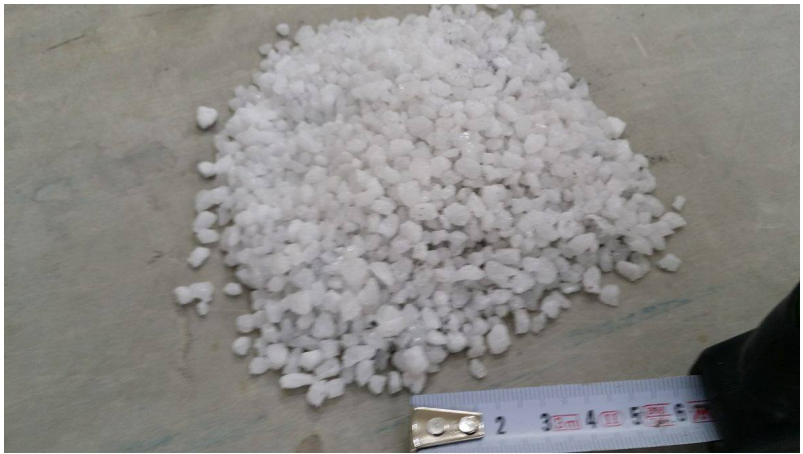

Figure 1. Corundum, fraction 3-5 mm.

ples were tested by a projectile with impact velocity in the range of $510-850 \mathrm{~m} / \mathrm{s}$, an average mass of $341.2 \mathrm{~g}$ and a diameter of $25.3 \mathrm{~mm}$. From the results, it was concluded that when the aggregate grain size increases, the concrete achieves higher compressive strengths. When the fraction was changed from 5-20 mm to 35$45 \mathrm{~mm}$, the compressive strength increased by $18 \%$.

In terms of depth of penetration (DOP) of the projectile, it can be stated that when the aggregate grain size is increased from $0.5 d$ (where $d$ is the diameter of the projectile) to $1.5 d$ and $2.5 d$ its value decreases gradually. With increasing grain size of filler, the probability of a direct hit of coarse aggregate particles increases. Therefore, it is possible in this way greatly enhance impact resistance of UHPSFRC, if coarse aggregate with high hardness and strength is used.

The surface of the crater after the impact of the projectile decreases as the grain size of the added coarse aggregate increases. Slightly better results are also obtained when the content of corundum in the mixture is increased. The average surface area of the crater with $45 \%$ corundum content was $12.5 \%$ smaller compared to the $30 \%$ corundum content [4].

Within the experimental program, six types of samples were proposed - one reference mixture and five other mixtures with a variable percentage of corundum $(10 \%, 15 \%, 20 \%, 22.5 \%$ and $30 \%)$. All slabs were made in a thickness of $50 \mathrm{~mm}$ and a size of $400 \times 300 \mathrm{~mm}$. The steel fibres were $13 \mathrm{~mm}$ in length and $0.15 \mathrm{~mm}$ in diameter. The amount of added fibres for all samples was $1.5 \%$ by volume of the resulting composite.

A dry prefabricated mixture of a multifunctional silicate composite [8] was used, to which the corundum was added. This prefabricated mixture comprises a cement matrix which forms a ground cement clinker with a specific surface area of more than $150 \mathrm{~m}^{2} / \mathrm{kg}$. The dry prefabricated mixture contains the high-range water reducer, a defoaming agent, silica-fume, silica powder and fine sands with a maximal grain size of $1.2 \mathrm{~mm}$. The number of individual components can be seen in Table 1 The water to cement ratio of this mixture was 0.3 . Two kinds of samples were made with the prefabricated mixture with $10 \%$ and $15 \%$ content of corundum from the total volume of the composite. The corundum was used in a $3-5 \mathrm{~mm}$ fraction; its

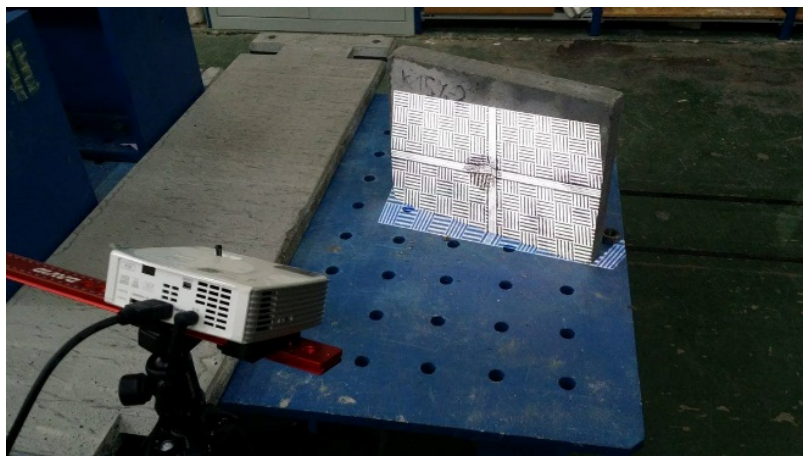

Figure 2. Capture the crater by using a 3D scanner.

bulk density was $3850 \mathrm{~kg} / \mathrm{m}^{3}$. The producer did not provide us with the granulometry of this fraction.

For further corundum samples, a custom mixture was designed to meet optimized HPSFRC granulometry. As well as prefabricated mixture it contained silica powder, microsilica, a superplasticizer and a defoaming agent. The composition of this mixture can be seen in Table 2 In this recipe, corundum replaced fine aggregates in $15 \%, 22.5 \%$ and $30 \%$ of the total aggregates content. The mixture uses a cement class 52.5 , the water-to-cement ratio was designed to 0.3 .

\section{ExPERIMENTAL PROGRAMME}

Besides the slabs, three beams of $160 \times 40 \times 40 \mathrm{~mm}$ from each mixture were made. For these samples was performed a three-point test for flexural strength. Average strengths and bulk densities of materials are shown in Table 3 . The table is supplemented with the average values of HPSFRC samples made from a dry prefabricated mixture of multifunctional silicate composite without added coarse aggregate.

Prepared slabs of $400 \times 300 \times 50 \mathrm{~mm}$ were subjected to a projectile impact $7.62 \times 39$ in the shooting range. It is a $7.62 \mathrm{~mm}$ full-metal jacket with a soft lead core. The weight of this projectile was $8.04 \mathrm{~g}$, the velocity of the projectile is around $710 \mathrm{~m} / \mathrm{s}$. In previous experiments, UHPSFRC slabs $50 \mathrm{~mm}$ thick without added coarse aggregate stopped this type of projectile, so it is assumed that the plates with coarse aggregate should also resist this type the projectile [9].

Evaluation of the results was carried out by using the 3D scanner David, which employs two-picture photogrammetry (stereophotogrammetry). For each sample, the crater on the front side was captured using this 3D scanner (Figure 2).

The scanner was placed at a suitable distance and the correct resolution was set and the surface image of the board was scanned (Figure 3). To capture the entire surface of the crater were taken pictures from four different angles. These four pictures were putted together by software DAVID and created one final 3D picture of crater.

The resulting surface was exported in .obj format and subsequently processed in Autocad Civil 3D software. Then, in this program, from the files that 


\begin{tabular}{cl}
\hline Mass proportions & Component \\
\hline 1 & Binder \\
0.1 & Active form $\mathrm{SiO}_{2}$, so called microsilica \\
0.25 & Silica powder (fraction d50 - around $6 \mu \mathrm{m})$ \\
1.6 & Silica sand with smooth granulometry \\
0.01 & $(0.1-1.2$ mm medium size grain d50 - around $500 \mu \mathrm{m})$ \\
0.001 & High range water reducer (Superplasticizer) \\
\hline
\end{tabular}

TABLE 1. Components of the prefabricated mixture - proportions by weight.

\begin{tabular}{lcccccc}
\hline Composition & HPSFRC & $\begin{array}{c}\text { Corundum } \\
10 \%\end{array}$ & $\begin{array}{c}\text { Corundum } \\
15 \%\end{array}$ & $\begin{array}{c}\text { Corundum } \\
20 \%\end{array}$ & $\begin{array}{c}\text { Corundum } \\
22.5 \%\end{array}$ & $\begin{array}{c}\text { Corundum } \\
30 \%\end{array}$ \\
\hline Cement & 1 & & & & & \\
Additives & 0.4 & & & & & \\
Water & 0.3 & & & & & \\
HRWR & 0.025 & & & & & \\
Fine sands & 1.76 & 1.59 & 1.50 & 1.42 & 1.36 & 1.23 \\
Corundum & 0 & 0.17 & 0.26 & 0.34 & 0.40 & 0.53 \\
\hline
\end{tabular}

TABLE 2. Composition of high-performance concrete with corundum.

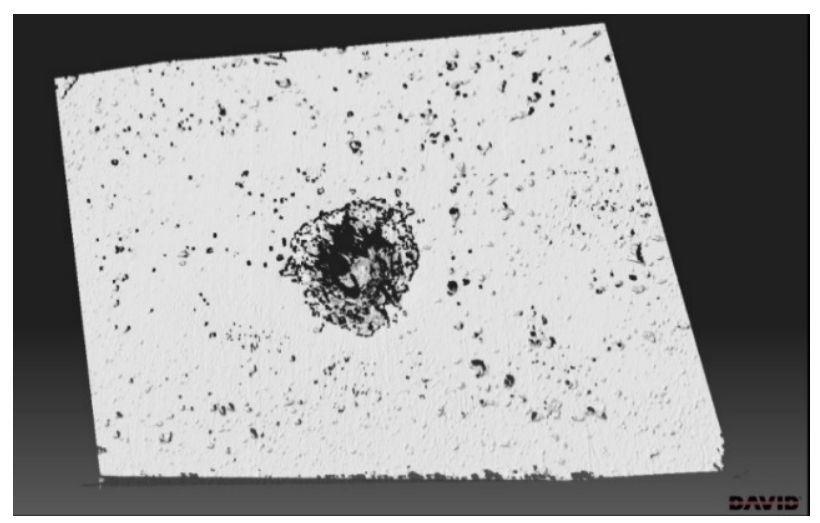

Figure 3. Picture the surface of the board.

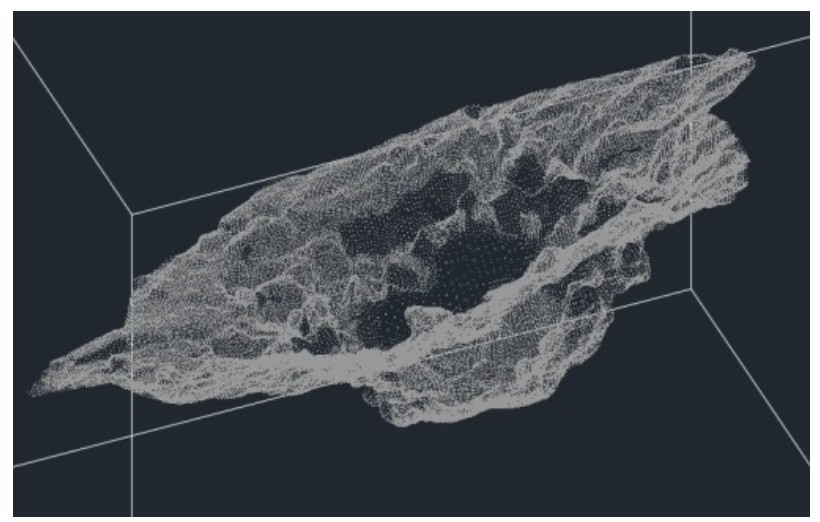

Figure 4. Picture of crater surface in AutoCAD Civil 3D using point cloud. contained the 3D coordinates of the scanned craters, it created a point cloud (Figure 4). The software then created a 3D surface and was able to measure the area of the crater (3D surface), diameter of the created crater and the penetration depth of the projectile.

\section{Results And Discussion}

The resulting values of diameter and depth of penetration of the surface craters were obtained using AutoCAD Civil 3D are shown in Tab. 4

The following graph (Figure 5 ) shows that adding $10 \%$ and $15 \%$ corundum aggregates leads to a decreasing penetration depth of $23.4 \mathrm{~mm}$ to $20.7 \mathrm{~mm}$ and at a further increase of corundum content the DOP even decrease slightly to $19.7 \mathrm{~mm}$. For samples of designed HPSFRC mixture, with increasing amount of corundum is achieved to reduce a depth of penetration from $23.4 \mathrm{~mm}$ to $19.7 \mathrm{~mm}$.

The chart in Figure 5 shows the dependence of the depth of penetration on the amount of corundum added. In general, it can be stated, that with the increasing amount of aggregate, the depth of penetration decreases, but the optimal composition of the mixture must be still found. If the grain curve is not filled with sufficient fine grain aggregate, it will occur to microcracks of the composite due to insufficient compaction of the mixture.

The next chart (Figure 6) shows the dependence of the diameter of the crater on the amount of corundum added. With the higher content of coarse aggregate in HPSFRC, the diameter of the crater formed by the impact of a projectile is decreasing. In the prefabricated mixture, when the corundum is increased from $10 \%$ to $20 \%$, the crater diameter is reduced from $81 \mathrm{~mm}$ to $68.2 \mathrm{~mm}$. On the contrary, when com- 


\begin{tabular}{lcccc}
\hline Mixture & $\begin{array}{c}\text { Corundum } \\
{\left[\mathrm{kg} / \mathrm{m}^{3}\right]}\end{array}$ & $\begin{array}{c}\text { Compressive strength } \\
{[\mathrm{MPa}]}\end{array}$ & $\begin{array}{c}\text { Tensile strength } \\
{[\mathrm{MPa}]}\end{array}$ & $\begin{array}{c}\text { Density } \\
{\left[\mathrm{kg} / \mathrm{m}^{3}\right]}\end{array}$ \\
\hline HPSFRC & 0 & 158.0 & 25.60 & 2373 \\
Corundum 10\% & 119.5 & 164.6 & 30.19 & 2293 \\
Corundum 15\% & 181.1 & 164.2 & 30.86 & 2400 \\
Corundum 20\% & 239.0 & 173.3 & 28.16 & 2433 \\
Corundum 22.5\% & 296.4 & 163.5 & 31.25 & 2391 \\
Corundum 30\% & 375.0 & 170.4 & 26.40 & 2468 \\
\hline
\end{tabular}

TABLE 3. Mechanical properties of high-performance concrete with corundum.

\begin{tabular}{lcccc}
\hline Samples & $\begin{array}{c}\text { DOP } \\
{[\mathrm{mm}]}\end{array}$ & $\begin{array}{c}\text { Diameter } \\
{[\mathrm{mm}]}\end{array}$ & $\begin{array}{c}2 \text { D surface } \\
{\left[\mathrm{mm}^{2}\right]}\end{array}$ & $\begin{array}{c}3 \text { D surface } \\
{\left[\mathrm{mm}^{2}\right]}\end{array}$ \\
\hline Corundum 10\% & 20.7 & 81.0 & 5158 & 43095 \\
Corundum 15\% & 23.4 & 77.2 & 4688 & 39619 \\
Corundum 20\% & 19.7 & 68.2 & 3710 & 47967 \\
Corundum 22.5\% & 20.7 & 75.6 & 4506 & 40107 \\
Corundum 30\% & 19.7 & 66.7 & 3506 & 28384 \\
\hline
\end{tabular}

TABLE 4. Crater dimensions of UHPFRC after projectile impact.

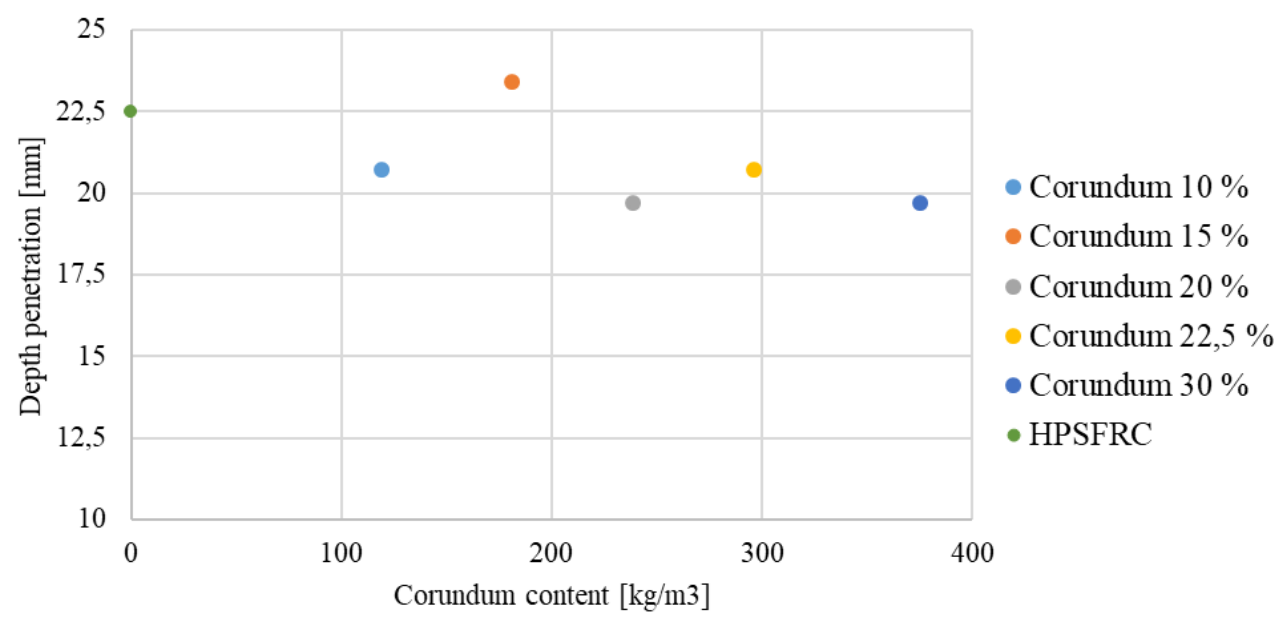

Figure 5. Dependence of depth penetration on corundum content.

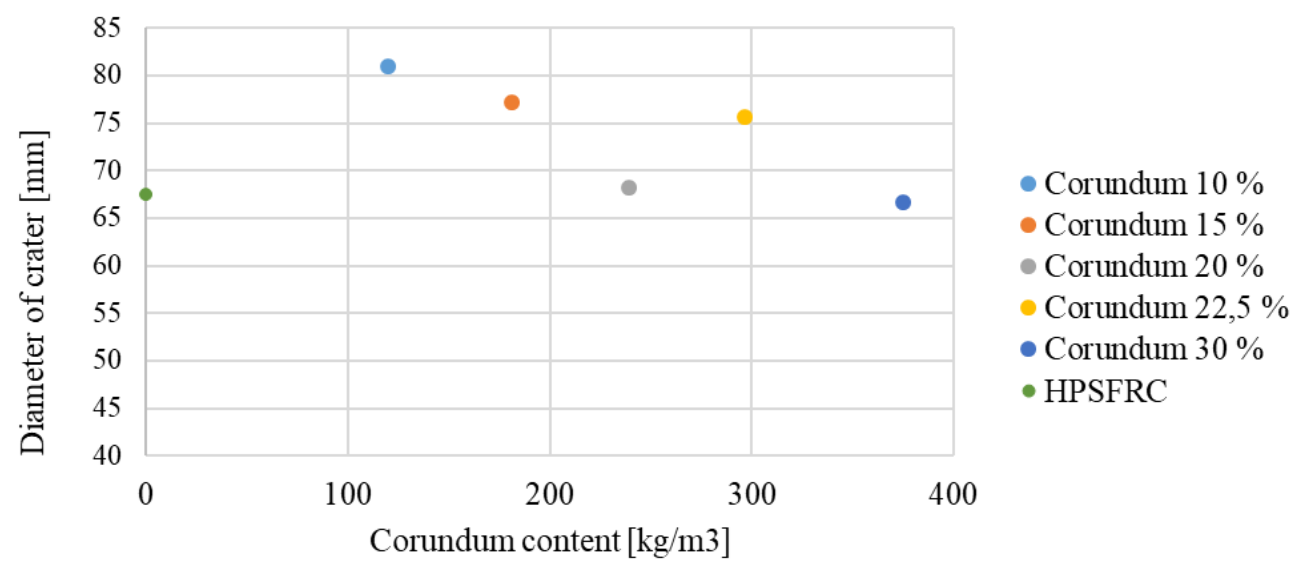

Figure 6. Dependence of crater diameter on corundum content. 
paring the mixture with $22.5 \%$ and $20 \%$ corundum, the crater diameter drops from $75.6 \mathrm{~mm}$ to $66.7 \mathrm{~mm}$. Other variations in the crater diameter are due to the diversity between prefabricated and a custom mixture. Both mixtures have different amount of fine sands and corundum aggregate. That's why the corundum sample has a $22.5 \%$ larger crater diameter than corundum $20 \%$, even if there is coarser aggregate.

\section{Conclusions}

In terms of resistance to impact of the projectile, it has been found the addition of coarse corundum aggregate to high-performance steel-fibre-reinforced concrete (HPSFRC) has a positive effect on its impact resistance. The depth of penetration, as well as the diameter of the crater, depends on the compressive strength of the composite and the amount of aggregate added. The higher the compressive strength of the material and the coarser aggregate added to the HPSFRC, the better the impedance properties the material proves. These properties also depend on the quality of the added aggregate, especially on its strength and hardness.

Coarse aggregates have shown great potential to improve the resistance of HPSFRC, as the addition of a higher amount of corundum has improved the HPFSRC impact behaviour.

The aim of this article was not to compare the benefits of corundum depending on the price. However, as literature shows, in larger structures the higher corundum price is defended in case of a significant improvement in the resistance to the projectile impact.

\section{ACKNOWLEDGEMENTS}

This paper was prepared as a part of research supported by the CTU in Prague [project No. SGS18/057/OHK1/1T/11]. The authors gratefully ac- knowledge the financial support from the Ministry of Industry of the Czech Republic [project No. FV10547].

\section{REFERENCES}

[1] P. Máca, R. Sovják, P. Konvalinka. Mix design of UHPFRC and its response to projectile impact. International Journal of Impact Engineering 63:158-163, 2014. DOI:10.1016/j.ijimpeng.2013.08.003

[2] V. Corinaldesi, G. Moriconi. Mechanical and thermal evaluation of ultra high performance fiber reinforced concretes for engineering applications. Construction and Building Materials 26:289-294, 2012. DOI:10.1016/j.conbuildmat.2011.06.023.

[3] R. Yu, P. Spiesz, H. Brouwers. Mix design and properties assessment of ultra-high performance fibre reinforced concrete (UHPFRC). Cement and Concrete Research 56:29-39, 2014. DOI:10.1016/j.cemconres.2013.11.002

[4] H. Wu, Q. Fang, J. Gong, et al. Projectile impact resistance of corundum aggregated UHP-SFRC. International Journal of Impact Engineering 84:38-53, 2015. DOI:10.1016/j.ijimpeng.2015.05.007

[5] M.-H. Zhang, V. Shim, G. Lu, C. Chew. Resistance of high-strength concrete to projectile impact. International Journal of Impact Engineering 31:825-841, 2005. DOI:10.1016/j.ijimpeng.2004.04.009

[6] H. Langberg, G. Markeset. High performance concrete-penetration resistance and material development. In Proceedings of the ninth international symposium on interaction of the effects of munitions with structures, pp. 933-941. 1999.

[7] H. Wu, Q. Fang, X. Chen, et al. Projectile penetration of ultra-high performance cement based composites at $510-1320 \mathrm{~m} / \mathrm{s}$. Construction and Building Materials 74:188-200, 2015. DOI:10.1016/j.conbuildmat.2014.10.041.

[8] K. Kolář, Z. Bažantová, P. Konvalinka. Suchá prefabrikovaná směs silikátového kompozitu. Patent, Úřad průmyslového vlastnictví, 2015.

[9] T. Vavřiník. Odolnost vysokohodnotného betonu proti nárazu projektilu. Bachelor thesis, Fakulta stavební, ČVUT v Praze, 2012. 